\title{
The relationship between level of the red cell distribution width and the outcomes of patients who acquired pneumonia from community Yousef A. Yousef, Mahmoud A. Manal
}

Background Inflammatory and oxidative stress caused by infection has recently been proposed as a mechanism of association between the red cell distribution width (RDW) and infectious diseases, such as community-acquired pneumonia (CAP).

Objective The present goal was to assess the prognostic importance of the RDW test in patients with CAP.

Patients and methods The present research was a descriptive and prospective study of patients diagnosed with CAP. All were admitted to Chest Department of Assiut University Hospital between April 2017 and July 2018. Assessment of CAP severity at time of hospital admission using Pneumonia Severity Index was done for all enrolled patients. Complete blood count was measured by automated hematology analyzer, and RDW was reported as a part of the complete blood count result. Normal reference range of RDW was $11.5-14.5 \%$. All of the patients were followed up until being discharged. The outcome variable was in-hospital mortality.

Results The current study involved 94 patients with CAP: 77 (82\%) survived and 17 (18\%) died. RDW level was significantly higher in nonsurvivors compared with survivors (18.52 \pm 3.07 vs. $12.76 \pm 2.08 ; P=0.022$ ). A significant positive relationship was found between RDW level and Pneumonia Severity Index points $(r=0.664 ; P=0.000)$. Regarding the

\section{Introduction}

Community-acquired pneumonia (CAP) is a common infectious disease, and it is a major cause of morbidity and mortality worldwide [1,2]. Scoring systems, including CURB-65 and Pneumonia Severity Index (PSI), and novel biomarkers, including procalcitonin (PCT) and C-reactive protein (CRP), are useful for predicting CAP outcomes, but all have their own strengths and weaknesses [3-5]. PSI and CURB-65 scoring systems have been evidenced to have positive correlations with mortality in patients with severe CAP. The PSI scoring system is time intensive owing to more than 20 elements in its questionnaire. The CURB-65 scoring system was controversial in elderly patients [5-8]. Serum PCT, as a novel biomarker, is a valuable single predictor in the assessment of severe CAP, the same as CRP [8]. In developing countries, PCT and CRP tests are not promptly available for every patient [9-12]. On the contrary, complete blood count $(\mathrm{CBC})$ test is a simple, valuable, inexpensive, and readily available measurement. White blood cell (WBC) count is one of the $\mathrm{CBC}$ components that traditionally is used as a diagnostic performance of the RDW test, it was observed that RDW level at cutoff point more than $16.1 \%$ had $94.12 \%$ sensitivity and $98.70 \%$ specificity for the prediction of inhospital mortality in patients with CAP.

\section{Conclusion The present data indicated that the} measurement of RDW on admission may provide the physician with a tool to predict the outcomes of patients with CAP and thus assist in decision making and management in such cases either alone or alongside the other well-

established means, taking into account that RDW testing is simple, cheaper, and readily available.

Egypt J Bronchol 2019 13:738-742

(C) 2020 Egyptian Journal of Bronchology

\section{Egyptian Journal of Bronchology 2019 13:738-742}

Keywords: community-acquired pneumonia, outcomes, red cell distribution level

Department of Chest Diseases and Tuberculosis, Assiut University Hospital, Assiut, Egypt

Correspondence to Manal A. Mahmoud, MD Degree of Chest Diseses and Tuberulosis; Department of Chest Diseases and Tuberculosis, Assiut University Hospital, Assiut, 71515, Egypt. Tel: +20 100949 3236;

fax: 088-2332278 - 2080278;

e-mail: manal_elkhawaga@yahoo.com

Received: 25 July 2019 Accepted: 24 November 2019

Published: 21 January 2020

biomarker in assessment of CAP severity; however, it has become less relied upon owing to its lower sensitivity and specificity compared with the more promising CRP and PCT [13]. Red cell distribution width (RDW) is also reported as one of parameters routinely analyzed in peripheral blood counts that reflects the heterogeneity of red cell size and has been traditionally used in diagnosing certain anemias. Inflammatory and oxidative stress caused by infection has recently been proposed as a mechanism of association between RDW and infectious diseases such as CAP [14-16]. In this context, some studies on patients with CAP focused on single RDW measurements at hospital admission [17-19]. Others have considered RDW as a dynamic parameter, with rapid changes during the course of the disease that requires repeated measurement during

This is an open access journal, and articles are distributed under the terms of the Creative Commons Attribution-NonCommercial-ShareAlike 4.0 License, which allows others to remix, tweak, and build upon the work non-commercially, as long as appropriate credit is given and the new creations are licensed under the identical terms. 
hospitalization to improve the prognostic performance [20]. As we belong to a developing country, that is, Egypt, the present goal was to assess the prognostic importance of the RDW test as a simple, cheap, and presumably useful measure in patients with CAP.

\section{Patients and methods}

This is a prospective descriptive study of 94 patients aged 18 years or older diagnosed to have CAP. All were admitted to Chest Department, Assiut University Hospital, between April 2017 and July 2018. The study protocol was approved by the Local Ethics Committee, and informed consent was obtained from all patients or those responsible for them. CAP was defined as the presence of a new pulmonary infiltrate on chest radiography and symptoms correspond to pneumonia such as cough, breathlessness, rising body temperature, and/or chest pain, which were not acquired in a hospital. The exclusion criteria included patients under the age of 18 years, as well as those with previous use of oral steroids (? $10 \mathrm{mg}$ prednisone equivalent per day for at least 2 weeks); taking medications that suppress the immunity; had tuberculosis; had human immunodeficiency virus infection; had active malignancy; had primary hematological disorders; and were hospitalized within the preceding 21 days.

Basic clinical information was obtained, and a bedside assessment was performed for each patient. The laboratory data and the chest radiographic findings were also collected. Assessment of CAP severity at time of hospital admission using PSI was done for all enrolled patients. $\mathrm{CBCs}$ were measured by an automated hematology analyzer (ADVIA 2120i Hematology Systems; Siemens Healthcare Diagnostics, Ballina, Ireland) during the first day of hospitalization, and RDW was reported as a part of the $\mathrm{CBC}$ results. Normal reference range of RDW was $11.5-14.5 \%$. All of the patients were followed up until being discharged. The outcome variable was inhospital mortality.

\section{Statistical analysis}

Data were collected and analyzed using SPSS (Statistical Package for the Social Science, version 20; IBM, Armonk, New York, USA). Continuous data were expressed in the form of mean $\pm S D$, whereas nominal data were expressed in the form of frequency (percentage). $\chi^{2}$ test was used to compare the nominal data of different groups in the study, whereas Student $t$ test was used to compare mean of two different groups. Pearson correlation was used to determine the correlation between RDW with PSI. Diagnostic performance of RDW in predicting the outcome in patients with CAP was determined by receiver operating characteristic curve. Level of confidence was kept at 95\%, and $P$ value was significant if less than 0.05

\section{Results}

The characterized data of the included patients are summarized in Table 1 . The current study enrolled 94 patients with CAP, and of them, 77 (82\%) patients survived, whereas 17 (18\%) patients' health deteriorated and they died. Mean age of survivors was $57.73 \pm 13.61$ years whereas the mean age of nonsurvivors was $60.29 \pm 7.66$ years. Most patients in both survivors and nonsurvivors were male (57.1 and $52.9 \%$, respectively). Both survivors and nonsurvivors had insignificant differences regarding smoking status, presence of comorbidities, and history of previous antibiotics treatment. On the contrary, both groups had a significant difference regarding the chest

Table 1 Characteristics of 94 patients with communityacquired pneumonia enrolled in this study

\begin{tabular}{|c|c|c|c|}
\hline & $\begin{array}{l}\text { Survivors } \\
(N=77) \\
{[n(\%)]}\end{array}$ & $\begin{array}{c}\text { Nonsurvivors } \\
\begin{array}{c}(N=17) \\
{[n(\%)]}\end{array}\end{array}$ & $\begin{array}{c}P \\
\text { value }\end{array}$ \\
\hline \multicolumn{4}{|l|}{ Sex } \\
\hline Male & $44(57.1)$ & $9(52.9)$ & 0.752 \\
\hline Female & $33(42.9)$ & $8(47.1)$ & \\
\hline Age (years) (mean $\pm S D)$ & $57.73 \pm 13.61$ & $60.29 \pm 7.66$ & 0.455 \\
\hline \multicolumn{4}{|l|}{ Smoking status } \\
\hline Current smoker & $4(5.2)$ & 0 & \\
\hline Exsmoker & $18(23.4)$ & $3(17.6)$ & 0.518 \\
\hline Nonsmoker & $55(71.4)$ & $14(82.4)$ & \\
\hline \multicolumn{4}{|l|}{ Comorbidity } \\
\hline Heart disease & $14(18.2)$ & $3(17.6)$ & 1.000 \\
\hline Pulmonary disease & $43(55.8)$ & $7(41.2)$ & 0.273 \\
\hline Renal disease & $5(6.5)$ & $3(17.6)$ & 0.154 \\
\hline Liver disease & $8(10.4)$ & $3(17.6)$ & 0.412 \\
\hline Diabetes & $17(22.1)$ & $7(41.2)$ & 0.127 \\
\hline Previous antibiotic & $2(2.6)$ & 0 & 1.000 \\
\hline Multilobar CXR infiltrate & $15(15.1)$ & $9(52.9)$ & $0.029^{*}$ \\
\hline Hospital stay (days) & $8.33 \pm 4.35$ & $14.14 \pm 4.38$ & $0.045^{\star}$ \\
\hline $\begin{array}{l}\text { Pneumonia Severity } \\
\text { Index score }\end{array}$ & $\begin{array}{l}110.74 \\
\pm 45.56\end{array}$ & $140.47 \pm 30.09$ & $0.017^{\star}$ \\
\hline \multicolumn{4}{|c|}{ Pneumonia Severity Index level } \\
\hline Class II & $13(16.9)$ & 0 & $0.012^{\star}$ \\
\hline Class III & $9(11.7)$ & 0 & \\
\hline Class IV & $31(40.3)$ & $5(29.4)$ & \\
\hline Class V & 24 (31.2) & $12(70.6)$ & \\
\hline White blood cell $\left(\times 10^{9} / \mathrm{I}\right)$ & $10.91 \pm 5.90$ & $10.57 \pm 3.52$ & 0.822 \\
\hline Platelet $\left(\times 10^{9} / \mathrm{I}\right)$ & $\begin{array}{c}220.64 \\
\pm 113.49\end{array}$ & $262.76 \pm 75.02$ & 0.148 \\
\hline RDW (\%) & $12.76 \pm 2.08$ & $18.52 \pm 3.07$ & $0.022^{\star}$ \\
\hline
\end{tabular}

CXR, chest radiography; RDW, red cell distribution width. *Significant $P$ value. 


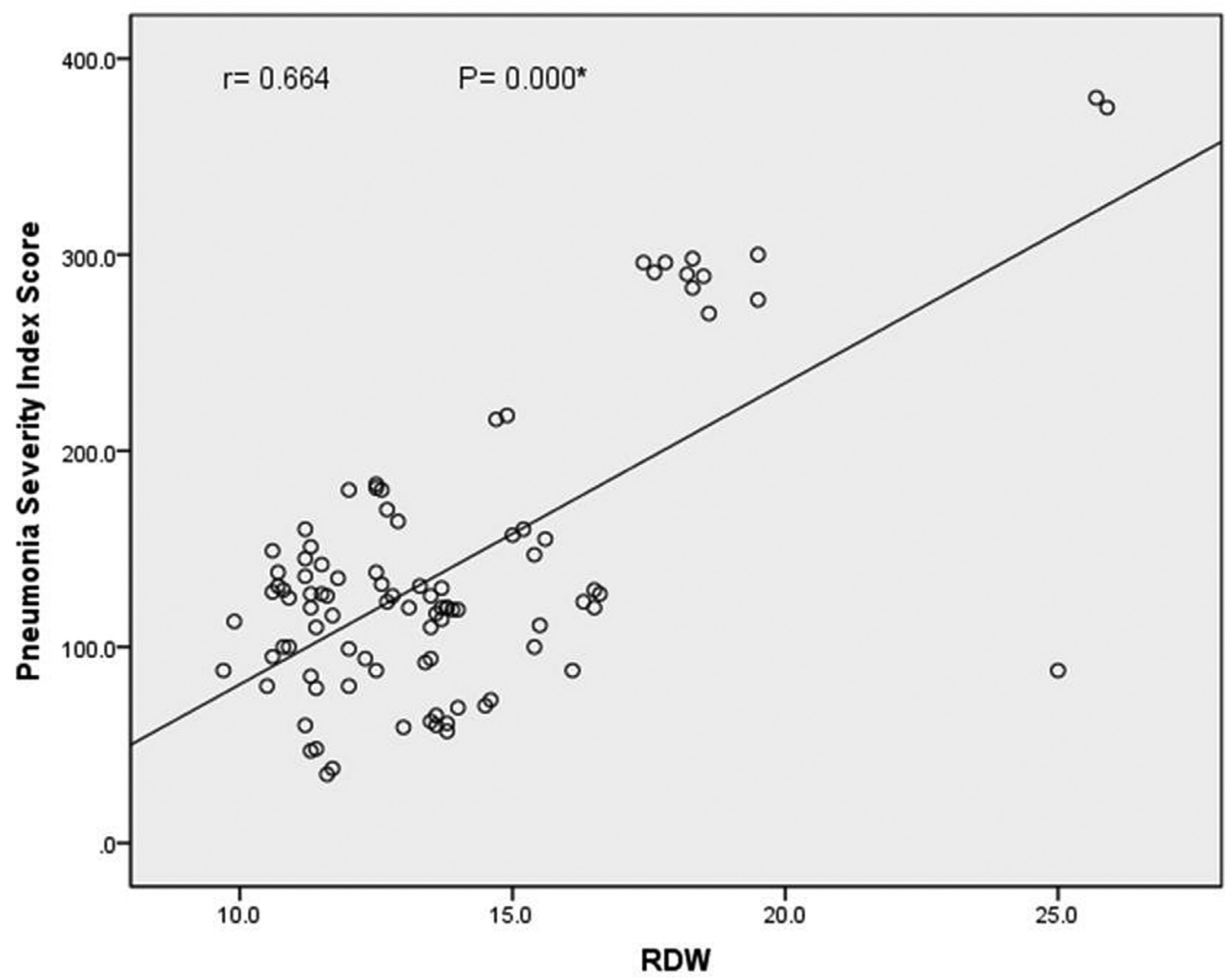

Correlation between RDW and PSI score of 94 patients with CAP. CAP, community-acquired pneumonia; PSI, Pneumonia Severity Index; RDW, red cell distribution width.

radiology infiltration and length of hospital stay. Mean PSI was also significantly higher in nonsurvivors in comparison with survivor $(140.47 \pm 30.09$ vs. 110.74 $\pm 45.56 ; P=0.017)$. Most nonsurvivors had PSI class $\mathrm{V}(70.6 \%)$, but only $31.2 \%$ of survivors had PSI class V. Statistical analysis of the CBC parameters among nonsurvivors and survivors showed insignificant differences as regarding WBCs and platelets counts. whereas RDW level was significantly higher in nonsurvivors compared with survivors $(18.52 \pm 3.07$ vs. $12.76 \pm 2.08 ; P=0.022)$. A significant positive relationship was found between RDW level and PSI points $(r=0.664, P=0.000)$, as shown in Fig. 1 . Of the study population, $67(71.3 \%)$ patients had normal RDW level in the CBC test whereas 27 (28.7\%) patients had high RDW level, and majority of them (70.4\%) had PSI class V, as shown in Table 2. The diagnostic performance of the RDW test in predicting deaths in patients with CAP is illustrated in Table 3 and Fig. 2. It was noticed that RDW level at cutoff point more than $16.1 \%$ had $94.12 \%$ sensitivity and 98.70\% specificity for the prediction of in-hospital mortality in patients with CAP.
Table 2 Distribution of red cell distribution width based on Pneumonia Severity Index class

\begin{tabular}{lccc}
\hline PSI class & $\begin{array}{c}\text { Normal RDW }(N=67) \\
{[n(\%)]}\end{array}$ & $\begin{array}{c}\text { High RDW }(N=27) \\
{[n(\%)]}\end{array}$ & $P$ value \\
\hline II & $13(19.4)$ & 0 & 0.003 \\
III & $7(10.5)$ & $2(7.4)$ & \\
IV & $30(44.8)$ & $6(22.2)$ & \\
V & $17(25.3)$ & $19(70.4)$ & \\
\hline
\end{tabular}

PSI, Pneumonia Severity Index; RDW, red cell distribution width.

\section{Discussion}

The relation between RDW levels and CAP is vague. However, different mechanisms have been suggested to explicate the association between RDW and the mortality. Weiss and Goodnough [21] reported that inflammation may increase RDW by compromising erythrocyte half-life, erythropoiesis, and the red cell membrane. Patel et al. [22] showed that decreased serum antioxidant levels and exposure to oxidative stress causes erythrocyte destruction and reduced life span. Katsoulis et al. [23] showed significantly lower total antioxidant status in patients with CAP compared with a control group. 
To our knowledge, this is the first study looking at the relation between the basal RDW level and the outcomes of patients with CAP who were admitted to Assiut University Hospitals. Our study was conducted upon 94 patients. The main results of our study showed that the RDW level was significantly

Table 3 Diagnostic performance of red cell distribution width in prediction of mortality in patients with community-acquired pneumonia

\begin{tabular}{lc}
\hline Indices & Value (\%) \\
\hline Sensitivity & 94.12 \\
Specificity & 98.70 \\
Positive predictive value & 94.1 \\
Negative predictive value & 98.7 \\
Accuracy & 97.87 \\
Cutoff point & $>16.1$ \\
Area under curve & 0.974 \\
\hline
\end{tabular}

higher in nonsurvivors than survivors. RDW had a significant positive relationship with the PSI score. Regarding the diagnostic performance of the RDW test, it was observed that RDW level at cutoff point more than $16.1 \%$ had $94.12 \%$ sensitivity and $98.70 \%$ specificity for the prediction of in-hospital mortality in patients with CAP.

Lee et al. [16] showed that high RDW more than $15.2 \%$ was associated with high mortality in 744 patients with CAP, and the patients had a mean age of 70.1 years. Braun and colleagues reported that high RDW more than $14.5 \%$ was associated with higher mortality and severe morbidity, independently of blood WBC and hemoglobin levels at time of presentation to hospital, in 637 patients with CAP, and the patients had a mean age of 46 years [16]. Braun et al. [17] reported that RDW more than $15 \%$ was correlated

Figure 2

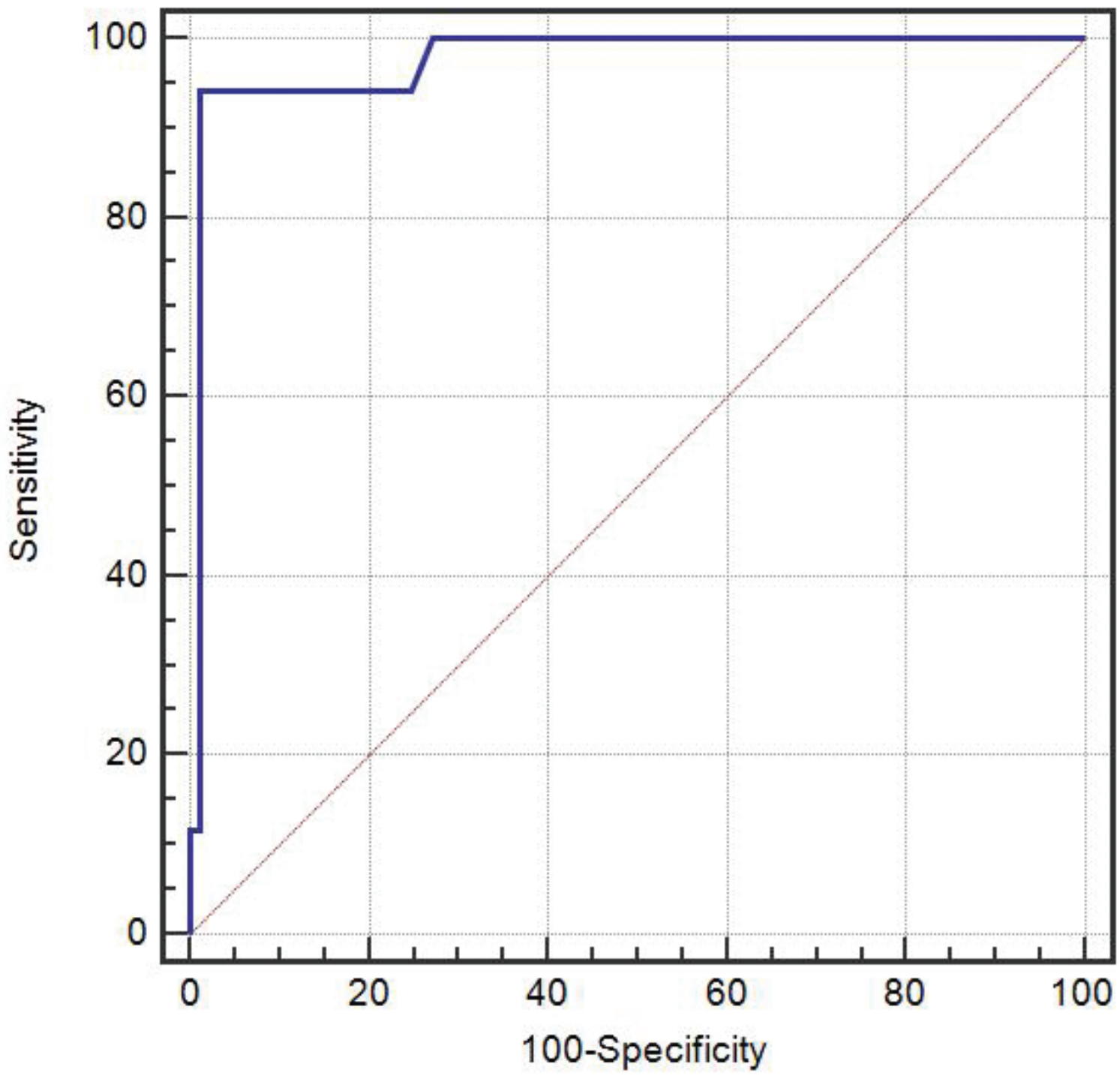

Receiver operating characteristic (ROC) curve for RDW in predicting in-hospital mortality of 94 patients with CAP. CAP, community-acquired pneumonia; RDW, red cell distribution width. 
with mortality in patients with CAP, who had a mean age of 69.9 years.

The reduction in the number of patients enrolled in our study compared with the aforementioned study is evident. Moreover, what can be considered as a limitation that should be noted is that the RDW level was recorded once upon admission, and it may be better to register it several times during the course of the disease and to determine any change in its level and relation to the outcome of the disease as described in the study by Lee $e t$ al. [20]. This may be more accurate, and on the contrary may help modify treatment.

\section{Conclusion}

In conclusion, the present data indicated that the measurement of RDW on admission may provide the physician with a tool to predict the outcomes of patients with CAP and thus assist in decision making and management in such cases either alone or alongside other well-established means, taking into account that RDW testing is simple, cheaper, and readily available.

\section{Financial support and sponsorship}

Nil.

\section{Conflicts of interest}

There are no conflicts of interest.

\section{References}

1 Adamuz J, Viasus D, Jimenez-Martinez E, Isla P, Garcia-Vidal C, Dorca J, et al. Incidence, timing and risk factors associated with 1-year mortality after hospitalization for community-acquired pneumonia. J Infect 2014; 68:534-541.

2 Aziz AOA, Fattah MTA, Mohamed AH, Aziz MOA, Mohammed MS. Mortality predictors in patients with severe community-acquired pneumonia requiring ICU admission. Egypt J Bronchol 2016; 10:155-161.

3 Ruiz de Oña Lacasta JM, Gómez Fernández M, Celdrán Gil J. Communityacquired pneumonia in inpatients: mortality, comorbidity and risk classes. Rev Clin Esp 2003; 203:64-67.

4 Varshochi M, Kianmehr P, Naghavi-Behzad M, Bayat-Makoo Z. Correspondence between hospital admission and the pneumonia severity index (PSI),CURB-65 criteria and comparison of their predictive value in mortality and hospital stay. Infez Med 2013; 2:103-110.
5 Akram AR, Chalmers JD, Hill AT. Predicting mortality with severity assessment tools in out-patients with community-acquired pneumonia. QJM 2011; 104:871-879.

6 Lam TH, Yau KP. Two unusual cases of severe dysbarism after compressed air work in Hong Kong. Undersea Biomed Res 1984; 11:381-385.

7 Micek ST, Lang A, Fuller BM, Hampton NB, Kollef MH. Clinical implications for patients treated inappropriately for community-acquired pneumonia in the emergency department. BMC Infect Dis 2014; 14:61.

8 Li HY, Guo Q, Song WD, Zhou YP, Li M, Chen XK, et al. CUR-65 score for community-acquired pneumonia predicted mortality better than CURB-65 score in low-mortality rate settings. Am J Med Sci 2015; 350:186-190.

9 Murillo-Zamora E, Medina-González A, Zamora-Pérez L, Vázquez-Yáñez A, Guzmán-Esquivel J, Trujillo-Hernández B. Performance of the PSI and CURB-65 scoring systems in predicting30-day mortality in healthcareassociated pneumonia. Med Clin (Barc) 2018; 150:99-103.

$10 \mathrm{Kim} \mathrm{MW,} \mathrm{Lim} \mathrm{JY,} \mathrm{Oh} \mathrm{SH.} \mathrm{Mortality} \mathrm{prediction} \mathrm{using} \mathrm{serum} \mathrm{biomarkers} \mathrm{and}$ various clinical risk scales in community-acquired pneumonia. Scand $J$ Clin Lab Invest 2017; 77:486-492.

11 Hohenthal U, Hurme S, Helenius H, Heiro M, Meurman O, Nikoskelainen J, et al. Utility of C-reactive protein in assessing the disease severity and complications of community-acquired pneumonia. Clin Microbiol Infect 2009; 15:1026-1132.

12 Wang X, Jiao J, Wei R, Feng Y, Ma X, Li Y, et al. A new method to predict hospital mortality in severe community acquired pneumonia. Eur $J$ Intern Med 2017; 40:56-63.

13 Shaddock EJ. How and when to use common biomarkers in communityacquired pneumonia. Pneumonia (Nathan) 2016; 28:17.

14 Pierce CN, Larson DF. Inflammatory cytokine inhibition of erythropoiesis in patients implanted with a mechanical circulatory assist device. Perfusion 2005; 20:83-90.

15 Ghaffari S. Oxidative stress in the regulation of normal and neoplastic hematopoiesis. Antioxid Redox Signal 2008; 10:1923-1940.

16 Lee JH, Chung HJ, Kim K, Jo YH, Rhee JE, Kim YJ, et al. Red cell distribution width as a prognostic marker in patients with communityacquired pneumonia. Am J Emerg Med 2013; 31:72-79.

17 Braun E, Domany E, Kenig Y, Mazor Y, Makhoul BF, Azzam ZS. Elevated red cell distribution width predicts poor outcome in young patients with community acquired pneumonia. Crit Care 2011; 15:R194.

18 Braun E, Kheir J, Mashiach T, Naffaa M, Azzam ZS. Is elevated red cell distribution width a prognostic predictor in adult patients with community acquired pneumonia? BMC Infect Dis 2014; 14:129.

19 Bello S, Fandos S, Lasierra AB, Mincholé E, Panadero C, Simon AL, et al. Red blood cell distribution width $[R D W]$ and long-term mortality after communityacquired pneumonia.A comparison with proadrenomedullin. Respir Med 2015; 109:1193-1206.

20 Lee SM, Lee JH, Kim K, Jo YH, Lee J, Kim J, et al. The clinical significance of changes in red blood cell distribution width in patients with communityacquired pneumonia. Clin Exp Emerg Med 2016; 3:139-147.

21 Weiss G, Goodnough LT. Anemia of chronic disease. N Engl J Med 2005; 352:1011-1023.

22 Patel KV, Ferrucci L, Ershler WB, Longo DL, Guralnik JM. Red blood cell distribution width and the risk of death in middle-aged and older adults. Arch Intern Med 2009; 169:515-523.

23 Katsoulis K, Kontakiotis T, Baltopoulos G, Kotsovili A, Legakis IN. Total antioxidant status and severity of community-acquired pneumonia: are they correlated? Respiration 2005; 72:381-387. 